\title{
Identification of Mass Movement Area in Liwa, Lampung Barat by Using Georadar and Geoelectricity Method
}

\author{
Yusraida Khairani ${ }^{1}$, Sismanto ${ }^{2}$, Moh. Ervan ${ }^{3}$, and Januar ${ }^{4}$ \\ Physics DepartementGadjah Mada University, Yogyakarta, Indonesia ${ }^{l}$ \\ Physics DepartementGadjah Mada University, Yogyakarta, Indonesia ${ }^{2}$ \\ Geological Survey Center, Bandung, Indonesia ${ }^{3}$ \\ Geological Survey Center, Bandung, Indonesia ${ }^{4}$ \\ yusraidakhairani@gmail.com
}

\begin{abstract}
Georadar method with radar reflection profiling configuration and geoelectrical method with dipole-dipole configuration has been done to determine the lithology, fracture characteristics of weak zone or fault that could potentially result of mass movement in Liwa, Lampung Barat. This research was conducted in 11 lines. Reflexwave software has been used in georadar data processing obtained from the result of GSSI surveyor 20 measurements. In addition, the Earthimager 2DINV software has been used in geoelectrical processing data from the measurement of multichannel supersting R8. Inversion from apparent resistivity to actual resistivity has been conducted to interpret subsurface section. The identified mass movement in this research have been indicated by the result of both methods the mass movement by line $1,2,5$ with the type of translation mass movement and line 5, 7, 8 with the type of creep mass movement. Liwa subsurface structure is arranged by quartenary sediment, clay (1-100 $\Omega \mathrm{m})$, sand $(8-4000 \Omega \mathrm{m})$ and igneous rock, granit $(5.000-1.000 .000 \Omega m)$ and from the results of the data analysis found that indication of a weak zone of the fault by line 1, $2,3,5,6$.
\end{abstract}

Keyword: Landslide, fracture, fault, georadar, geoelectricity.

\section{INTRODUCTION}

Based on the landslide disaster risk index map from the National Disaster Management Agency in 2010 (figure 1) shows that West Lampung Province is an area that has a high level of mass movement hazard is shown by the red image. West Lampung regency capital of Liwa traversed by Sumatra active fault lines segments Semangko which resulted in the island of Sumatra as vulnerable areas of disasters such as earthquakes and mass movements (landslides) [1].

This research use georadar and geoelectricity method to identify the mass movement area in the city of Liwa, West Lampung.

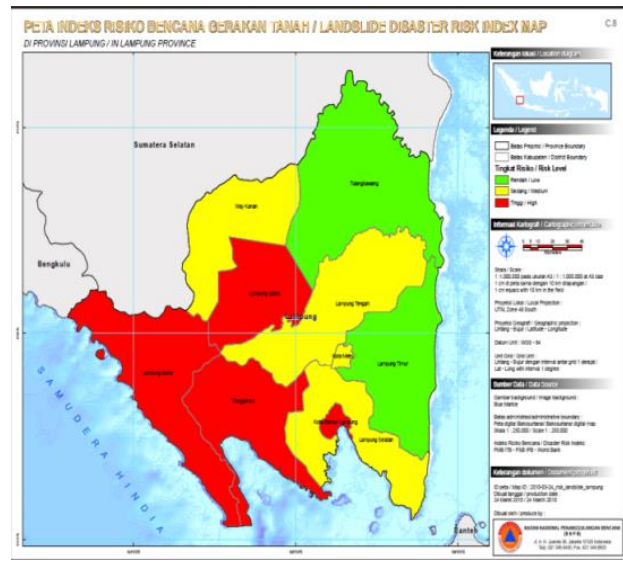

Figure 1. Landslide Disaster Risk Index Map in Lampung [8]

II. MASS MOVEMENT and GEORADAR

Mass movement is the movement of soil or rock mass from its original state at the direction of upright, horizontal or oblique, including slow or long-term deformation of a slope which is called creep [6]. Mass movement occurs when the driving force of material (gt) on slopes greater than friction force $(\mathrm{F})$ as shown in Figure 2. The driving force is generally influenced by the magnitude of the slope angle $(\alpha)$, water and heavy loads as well as types of soil or rocks. Friction force is generally influenced by the strength of rocks, soil density and friction forces between bedrock and soil weathering. The boundary between the bedrock and soil weathering is called slip plane.

Driving force $(\mathrm{g})$ greater and retention force $(F)$ is getting smaller if:

1. Slope angle $(\alpha)$ increases.

2. Rocks/ water-saturated soil.

3. There are areas of sliding, such as cracks field (joint or fault), the presence of boundary of rocks that pass of water and watertight (such as clay layer).

4. Vegetation bald.

5. Rocks / soil less solid.

6. Presence of vibration, whether caused by an earthquake, an 
explosion and vibration due to passing vehicles.

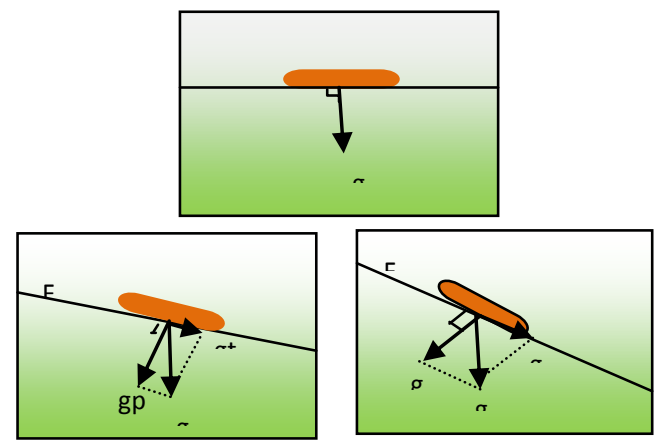

Figure 2. Mass movement on slopes

There are 6 types of mass movement or landslides, namely: translational landslide, avalanche rotation, movement of blocks, rubble stone, soil creep, and debris flow material. Translational and rotational landslide type occur most commonly in Indonesia. Most landslides claimed the lives of humans are debris flow material.

In areas where there are fault zones will simplify the process of weathering and water permeation, making it unstable and vulnerable to landslides.

In a radar system, a microwave emitted in all directions by the transmitter continuously. If an object is exposed to the waves, the signal will be reflected by the object and received by the receiver as shown in Figure 3. The reflected signal will provide information on the presence of objects that exist below the surface of the ground to be displayed by the radar screen.
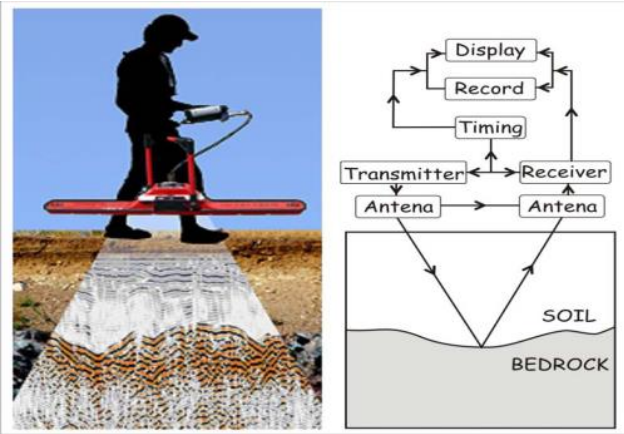

Figure 3. Principles Working GPR [3]

Maxwell's equations that can be used to understand the usage of the electromagnetic waves in a material as well as its application to determine the electrical properties of the material and magnetic [4]. One of the equations that shows the magnetic field caused by the electric field is:

$$
\bar{\nabla} \times \bar{H}=\frac{\partial \bar{D}}{\partial t}+\bar{J}
$$

and the equation which shows that the electric field resulting from the induced magnetic field that changes with time is:

$$
\begin{gathered}
\bar{\nabla} \times \bar{E}=-\frac{\partial \bar{B}}{\partial t} \\
\text { and } \bar{\nabla} \bullet \bar{B}=0 \\
\bar{\nabla} \bullet \bar{E}=\frac{\rho}{\varepsilon}
\end{gathered}
$$

where: $\bar{D}=\varepsilon \bar{E}, \bar{B}=\mu \bar{H}$ and $\bar{I}=\sigma \bar{E}$ and

$\bar{H}=$ the intensity of the magnetic field

(Ampere/m),

$\bar{E}=$ the intensity of the electric field

(Volt/m),

$\bar{D}=$ dipole moment density,

$\bar{B}=$ magnetic flux (Ampere $/ \mathrm{m})$,

$\bar{I}=$ conduction current density $\left(\right.$ Ampere $\left./ \mathrm{m}^{2}\right)$,

$\varepsilon=$ electric permittivity $($ Farad $/ \mathrm{m})$,

$\mu=$ magnetic permeability $(\mathrm{H})$,

$\sigma=$ electrical conductivity $\left(\mathrm{Ohm}^{-1} / \mathrm{m}\right)$,

$\rho=$ electric charge $\left(\mathrm{C} / \mathrm{m}^{2}\right)$,

By using Maxwell's equations (1) and (2), the electromagnetic wave equation can be derived as

$$
\begin{aligned}
& \bar{\nabla}^{2} \bar{E}-\mu \varepsilon \frac{\partial^{2} \bar{E}}{\partial t^{2}}=0 \\
& \bar{\nabla}^{2} \bar{H}-\mu \varepsilon \frac{\partial^{2} \bar{H}}{\partial t^{2}}=0
\end{aligned}
$$

permittivity $(\varepsilon)$, permeability $(\mu)$, and conductivity $(\sigma)$ determines the propagation of electromagnetic waves through a medium. Relative electric permittivity relates to the ability of the medium to polarize the electric field and determine the velocity of electromagnetic waves that run on a medium. For a different medium, the value $\varepsilon_{\mathrm{r}}$ (relative permittivity) will determine the value of the wave velocity in the medium. The conductivity of a mineral or rock should not be constant, depending on time, temperature, pressure and environmental factors. Unlike the permittivity and electrical conductivity properties, in geophysical exploration the values of permeability do not rely on the strong electric field, but the magnetic field [4]. 
According to Reynolds [7] radar wave velocity in the material $\left(V_{m}\right)$ is shown by the equation of:

$$
V_{m}=\frac{c}{\left\{\left(\frac{\varepsilon_{r} \mu_{r}}{2}\right)\left[\left(1+P^{2}\right)+1\right]\right\}^{1 / 2}}
$$

where $c$ : speed of light in the air; $\varepsilon_{\mathrm{r}}$ : the relative dielectric constant and $\mu_{\mathrm{r}}$ : relative magnetic permeability $\left(\mu_{\mathrm{r}}=1\right.$,for nonmagnetic materials); $P=$ loss factor; $P=\sigma / \varpi \varepsilon$

The comparison of reflected to initial energy is called the reflection coefficient $(\mathrm{R})$ is to determine the difference in the propagation of electromagnetic waves and more fundamentally is the difference of the relative dielectric constant of the adjacent medium. In all cases the magnitude of $\mathrm{R}$ is \pm 1 . Part of the transmitted energy is ( 1 to $\mathbb{R}$ ), while the power reflection coefficient (reflectance) is equal to $r^{2}$. The reflection coefficient $(R)$ is given by the equation:

$$
\begin{aligned}
R & =\frac{v_{1}-V_{2}}{v_{1}+V_{2}} \\
R & =\frac{-\sqrt{a_{2}}-\sqrt{a_{1}}}{-\sqrt{a_{2}}+\sqrt{a_{1}}}
\end{aligned}
$$

where:

$\mathbb{V}_{1}$ is the propagation of electromagnetic waves in layer 1 , and $V_{2}$ is the propagation of electromagnetic waves in layer $2, \mathbb{V}_{1}<\mathbb{V}_{2}$.

$\varepsilon_{1}$ dan $\varepsilon_{2}$ are relative dielectric constant of layer 1 and layer 2 .

Electric current $I$ passing through a cylindrical material (Figure 4) will be directly proportional to the cross-sectional area A, is directly proportional to the potential $\Delta V$ and inversely proportional to the length $L$, is

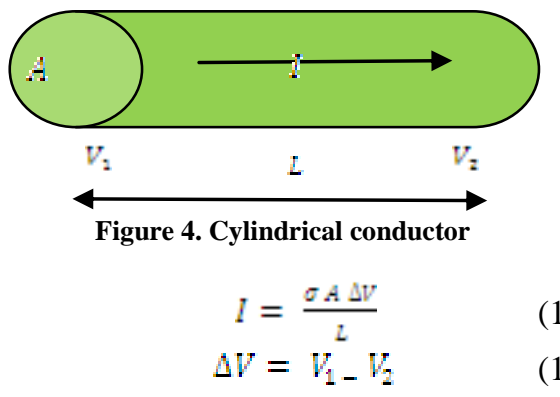

Geoelectric resistivity method has several configurations that are used in the measurement, i.e., Wenner, Schlumberger, pole-dipole, dipole-dipole configuration, and others. This configuration is distinguished by the arrangement of current electrode and potential electrode.

In the dipole-dipole configuration, two current electrodes and two potential electrodes are spaced apart by a distance $n a$, while the distance of each electrode is $a$. Then a measurements were performed by moving the electrode potential at a point where the current electrodes are fixed, then the removal of the current electrode at a distance of $n$ followed by subsequent removal of the electrode potential along the line so on until the current electrode measurements at the last point in the line (Figure 5).

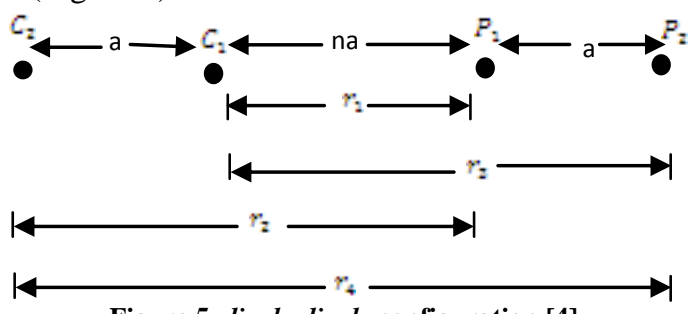

Figure 5. dipole-dipole configuration [4]

Based on the configuration, then the geometry factor for dipole-dipole configuration is:

$$
K=n(n+1)(n+2) \pi a
$$

\section{METHODS}

This research was conducted for 12 months which is April 2013 - March 2014. Location of the study in Liwa, West Lampung ( $4^{0} 47^{\prime} 16^{\prime \prime}-5^{0} 56^{\prime} 42^{\prime \prime}$ LS and $103^{0} 35^{\prime} 8$ " $-104^{0} 33^{\prime} 51^{\prime \prime}$ BT).

The instruments are used in this research is a set of equipment Georadar GSSI (Geophysical Survey Systems Inc) SIR-20 and Geoelectricity Multichannel Supersting R8

Data acquisition for georadar method performed using the $200 \mathrm{MHz}$ frequency antenna on each line measurements of topography at intervals of $100 \mathrm{~m}$ and to geolelectricity method done with a dipoledipole configuration with inter-electrode distance of six meters and a maximum line length measurement adjusted to the topography of the area of study. Georadar and geoelectric method measurements performed on the same line (figure 6). 


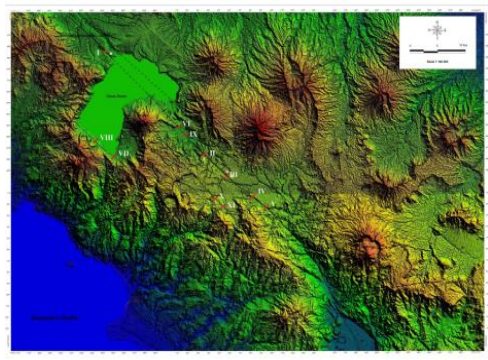

Figure 6. Lines (red lines) and area of georadar and geoelectricity measurement [1]

Data processing of georadar use Reflexwave software, where as the geoelectricity data are processed by Earthimager $2 D I N V$ modul. For georadar data based on the radargram analysis of subsurface rock types are interpreted through each facies radargram [2] as shown in Figure 7. Furthermore, for the data of geoelectricity on resistivity value adjusted for resistivity value [5].

\section{RESULTS AND DISCUSSION}

Georadar and geoelectric measurements in this research conducted at 11 lines through the fault of Sumatra, where 7 lines passes through the primary fault and 4 lines passes through the secondary fault segment Semangko. The position points are determined by using a GPS Garmin 76 CSX.

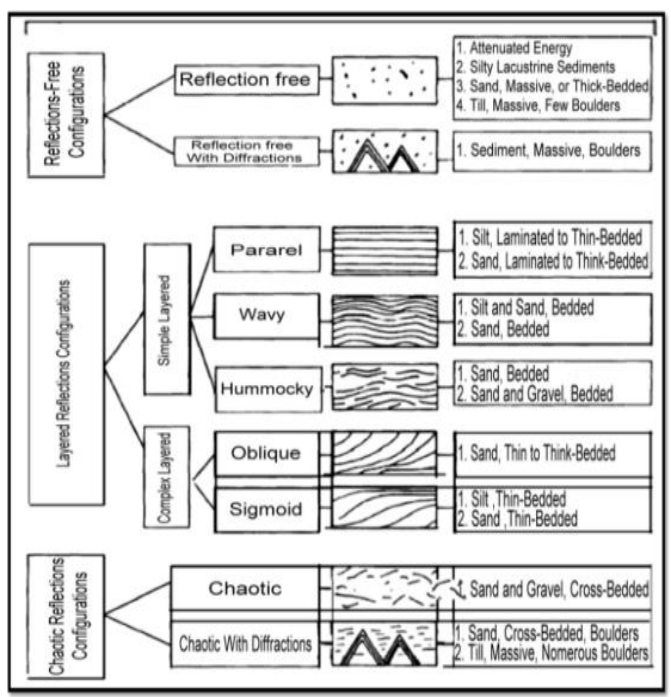

Figure 7. Determination of subsurface sediment types [2]
Georadar data collection used a transducer frequency of $200 \mathrm{~Hz}$ and performed perpendicular to the fault plane of Semangko Sumatra segments. An example result is shown on figure 8 .

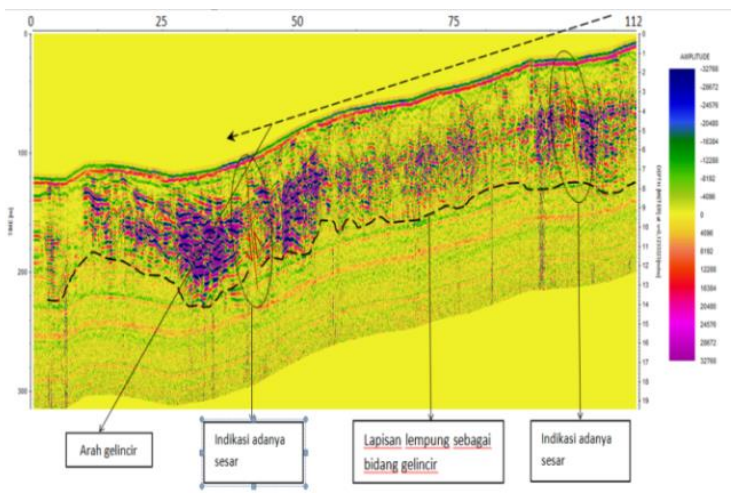

Figure 8. The results of georadar data processing on lines 5 and its interpretation

Geoelectricity data measurements in this study are conducted by the dipole-dipole configuration with inter-electrode spacing distance or a maximum is six meters and measurement lines length adjusted to the area of data retrieval. An examples of geoelectric data resulted on the figure 8 .

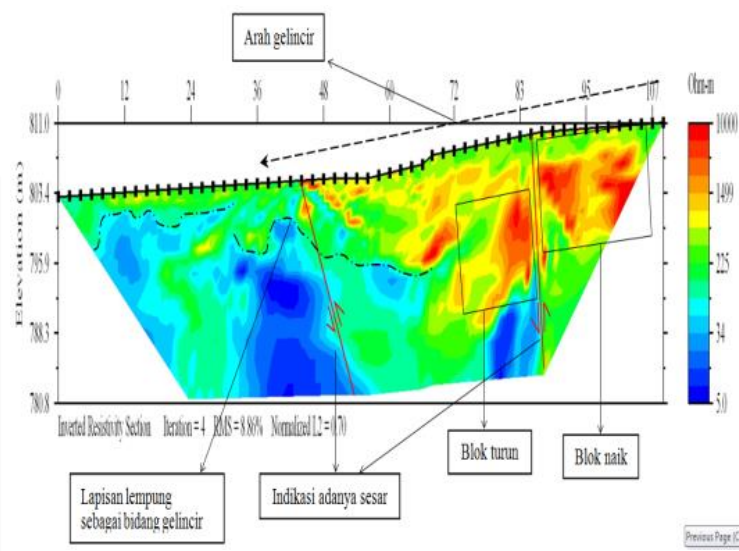

Figure 8. The results of geoelectricity data processing on lines 5 and its interpretation

The topography measurements of lines 5 is an undulating hills with lithological conditions of surface silty sand. The top layer at varying $0-8 \mathrm{~m}$ depth, with layered reflections in simple layered shaped configurations hummocky/subparalel middle sustained high amplitude estimated as sand and gravel. Then in the layer bounded below by the dotted line in black with varying 
depths 8 - $12 \mathrm{~m}$ with a reflection-free, lowamplitude and the possibility of a clay.

On the rocks with red-green color is a resistivity value of $(100-1000) \Omega m$, it is estimated to consist of sandstone, shale, weathered bedrock, to igneous rocks. Blue color with a resistivity value of $(55-100)$ $\Omega$ m estimated to be clay.

Addition of the line profile sketch shows a tilt angle varies from $0^{0}-53,13^{0}$, where the value is easy for the mass movement. At a distance of $46 \mathrm{~m}$ and $85 \mathrm{~m}$ are indicated as a fault shown in geoelectricity data and continuous to the surface is shown by georadar data in red line. If it rains then the sand slides and enter the clays through the fault formed.

Based on the results of the discussion above this area is a mass movement area and based of lines profile sketch can be classified on the type of translational mass movement which the sliding flat or wavy shaped ramps.

Compilation map showing vulnerable areas to mass movement and a safe area to mass movement are shown in Figure 9. The blue box is the lines indicated vulnerable by the mass movement of creep types, a yellow box indicated vulnerable of mass movement translational type, and brown box is the lines that safe area to mass movement.

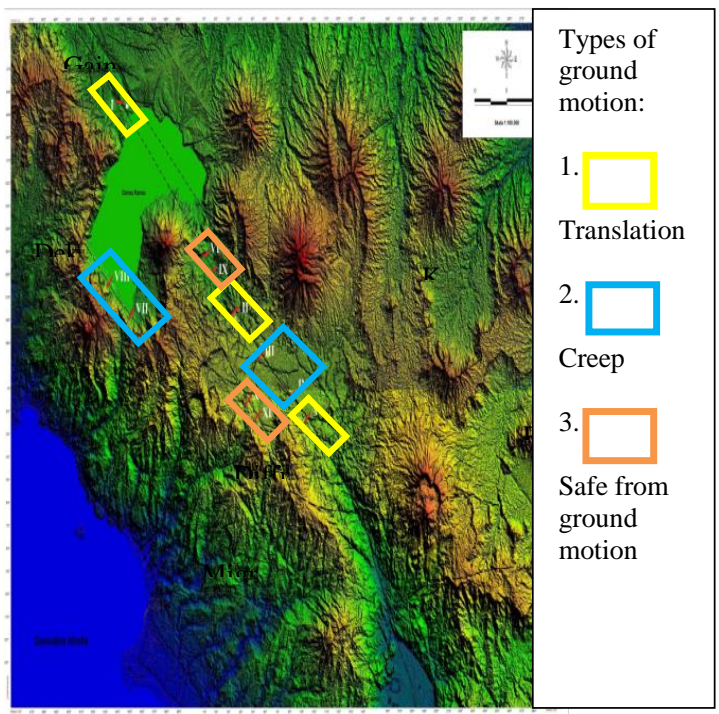

Figure 9. Map of the area which may experience of mass movement in Liwa, West Lampung

\section{CONCLUSION}

The Regional subsurface structure of Liwa, West Lampung are composed of clay stone with resistivity values (1-100 $\Omega \mathrm{m})$, sandstone with resistivity values $(8-4000$ $\Omega \mathrm{m})$, and as well as igneous rocks such as granite and tuff with resistivity values $(5.000$ $-1.000 .000 \Omega \mathrm{m}$ ). We find some indications of a weak zone of fault are on line 1 , line 2 , line 3 , line 5 and line 6 .

The interpretation of the data from radargram and resistivity revealed a number of some mass movement areas which are the area around the lines 1, 2, 5 with the type of translational mass movement and around the lines $3,4,7,8$ with the type of creep mass movement.

\section{REFERENCES}

[1]Asdani. S, Setiawan, J., dan Ervan, M., 2013, Penelitian dan Pemetaan Patahan Aktif Sumatera Segmen Semangko Lampung, Badan Geologi-Pusat Survei Geologi, Bandung. Diunduh pada tanggal 13 Oktober 2013, dari http://geosain.geology.esdm.go.id/bahan/ php/bacaonline.php?doc $=$ Executive Summary Patahan Aktif 2013.pdf.

[2]Beres, M., dan Haeni, F. P., 1991, Application of Ground Penetrating Radar Methods in Hydrogeologic Studies, Ground Water, Vol. 3, No. 29, 375-386.

[3]Ervan, M., 2013, Teori Dasar Ground Penetrating Radar, Puslitbang Geologi, Bandung.

[4]Keller, G.V., and Frischknecht, F.C., 1970, Electrical Methods in Geophysical Prospecting. Pergamon Press, Oxford.

[5]Loke, M.H., 2004, Tutorial: 2-D and 3-D Electrical Imaging Surveys for enviromental and engineering studies, Penang, Malaysia.

[6]Magetsari, N.A., Abdullah, C.I., Brahmantyo, B., 2000, Geologi Fisik, Bandung, ITB.

[7]Reynolds, J.M., 1997, An Introduction to Applied and Environmental Geophysics. John Willey And Sons, Chicester, England.

[8] http://geospasial.bnpb.go.id/wp-content /uploads/2010/06/2010-03-24_risk_ landslide_lampung.pdf. 